\title{
112. Tetrahymena Histone Sequences and their Implications for Phylogeny of Protozoa
}

\author{
By Hiroaki Hayashi, Minoru Nomoto, and Koichi IwaI \\ Institute of Endocrinology, Gunma University, Maebashi 371 \\ (Communicated by Shoei IsEKI, M. J. A., Nov. 12, 1980)
}

Histones are basic proteins associated with the nuclear DNA of eukaryotes. Usually, histones consist of five molecular species, $\mathrm{H} 1$, $\mathrm{H} 2 \mathrm{~A}, \mathrm{H} 2 \mathrm{~B}, \mathrm{H} 3$, and H4. Their amino acid sequences were first determined for calf thymus $\mathrm{H}^{1{ }^{1,2}}{ }^{2}$ and $\mathrm{H} 2 \mathrm{~B},{ }^{3)}$ and then for calf thymus $\mathrm{H}^{2} \mathrm{~A}^{4), 5)}$ and $\mathrm{H} 3{ }^{6}{ }^{6}$ followed by the sequencing of these histones from other animals and plants. Thus, it has been found that only two of the total 102 amino acid residues are different between the calf and pea $\mathrm{H} 4$ sequences, ${ }^{7)}$ and four of the 135 residues between the calf and pea $\mathrm{H} 3$ sequences, ${ }^{8}$ ) which are the largest differences among the known sequences of these two histones. However, we found that the $\mathrm{H} 2 \mathrm{~A}$ and H2B sequences are much more different between calf and pea. ${ }^{9)}$

The ciliate protozoan, Tetrahymena histones were first isolated by us, ${ }^{10)}$ followed by the fractionation and characterization of the five molecular species. ${ }^{11)}$ We have recently revised the isolation and fractionation procedures, and have now sequenced the $\mathrm{H} 4$ totally and the H2B partially. Strikingly, 20 residues differ between the Tetrahymena and calf $\mathrm{H} 4$ sequences, in spite of the fact that the histones from higher eukaryotes are the most highly conserved protein family known. ${ }^{12)}$ Differences in the H2B sequence between Tetrahymena and calf are also larger than those between calf and pea. These findings strongly suggest that the divergence of protozoa and higher eukaryotes is substantially earlier than that of animals and plants.

Materials and methods. An amicronucleate strain GL of Tetrahymena pyriformis was used. Cultures reaching the stationary state were continuously layered, at a flow rate of 1 liter $/ 10 \mathrm{~min}$, on $1.0 \mathrm{M}$ sucrose-3 mM CaCl $2-1 \mathrm{mM} \mathrm{MgCl}{ }_{2}-10 \mathrm{mM}$ Tris-HCl, $\mathrm{pH} 7.5$ containing $0.2 \%(\mathrm{v} / \mathrm{v})$ Nonidet P-40 (1 liter), placed in a Hitachi RPRC 18 rotor, during centrifugation at $10,000 \mathrm{rpm}(c a .10,000 \times \mathrm{g})$. This procedure omits the cell harvest step, removing the cell debris onto the surface of the sucrose solution and yielding nuclei as precipitate. The nuclei were further purified and washed with $0.15 \mathrm{M} \mathrm{NaCl}$, as described previously. ${ }^{13)}$

From the washed nuclei histones were extracted with $0.25 \mathrm{M}$ 
$\mathrm{HCl}$, and the extract was fractionated with $0.5 \mathrm{M} \mathrm{HClO}_{4}$ as described. ${ }^{14)}$ The precipitate fraction containing $\mathrm{H} 2 \mathrm{~A}, \mathrm{H} 2 \mathrm{~B}, \mathrm{H} 3$, and $\mathrm{H} 4$ was chromatographed on Bio-Gel P-60 with $20 \mathrm{mM} \mathrm{HCl}-0.02 \%$ $(\mathrm{w} / \mathrm{v}) \mathrm{NaN}_{3}$ containing $0.25 \mathrm{M} \mathrm{NaCl}$. The $\mathrm{H} 4$ fraction was highly pure. The H2B fraction was further purified by elution from the same column without $\mathrm{NaCl}$.

The sequencing of the $\mathrm{H} 4$ was done by manual Edman degradation of the intact protein and of the tryptic peptides separated by repeating column chromatography. The amino-acid phenylthiohydantoin derivatives were identified by high-pressure liquid chromatography and/or thin-layer chromatography. The H2B was sequenced by Edman degradation of the peptides preferentially cleaved at arginine residues with Clostripain (Worthington) and separated by repeating column chromatography. The larger peptides obtained by limited chymotrypsin digestion were also used.

Results. Fig. 1 shows the Tetrahymena H4 sequence deduced from the structure of the tryptic peptides, arranged by assuming homology with calf thymus H4. ${ }^{1)}$,2) The amino terminal of Tetrahymena $\mathrm{H} 4$ is not blocked; thus the first 17 residues were confirmed by manual Edman degradation of the intact protein. The first 53 residues are also consistent with similar results by automated degradation reported by Glover and Gorovsky. ${ }^{15)}$ The sequence of residue 54 through to the carboxy terminal is presented here for the first time, with the finding of microheterogeneity that about $14 \%$ of the total population has an additional arginine inserted between residues 88 and 89.

The Tetrahymena H2B sequence is shown in Fig. 2, which was deduced from the structure of the Clostripain peptides, arranged by assuming homology with calf thymus H2B. ${ }^{3}$ ) The amino terminal of Tetrahymena H2B is blocked; thus the first 28 residues are not completely sequenced, but the sequence is likely to differ largely from that of the first 34 residues of calf H2B. The subsequent region through to the carboxy terminal is relatively homologous between Tetrahymena and calf $\mathrm{H} 2 \mathrm{~B}$, with the same number of 91 residues. Besides the major component described above, some minor $\mathrm{H} 2 \mathrm{~B}$ variants appear to exist.

Further experiments for confirming the arrangement of tryptic or Clostripain peptides are now in progress. Nevertheless, the proposed sequences are sufficient to discuss the implications for the phylogeny of protozoa.

Discussion. Fig. 3 shows the number of differences in the H4 and $\mathrm{H} 2 \mathrm{~B}$ sequences between mammals, pea, and Tetrahymena. These sequences are compared for the major component of each histone. The mammal sequences are the same between calf,1,2) $\mathrm{pig}^{\left.1{ }^{16}\right)}$ and 


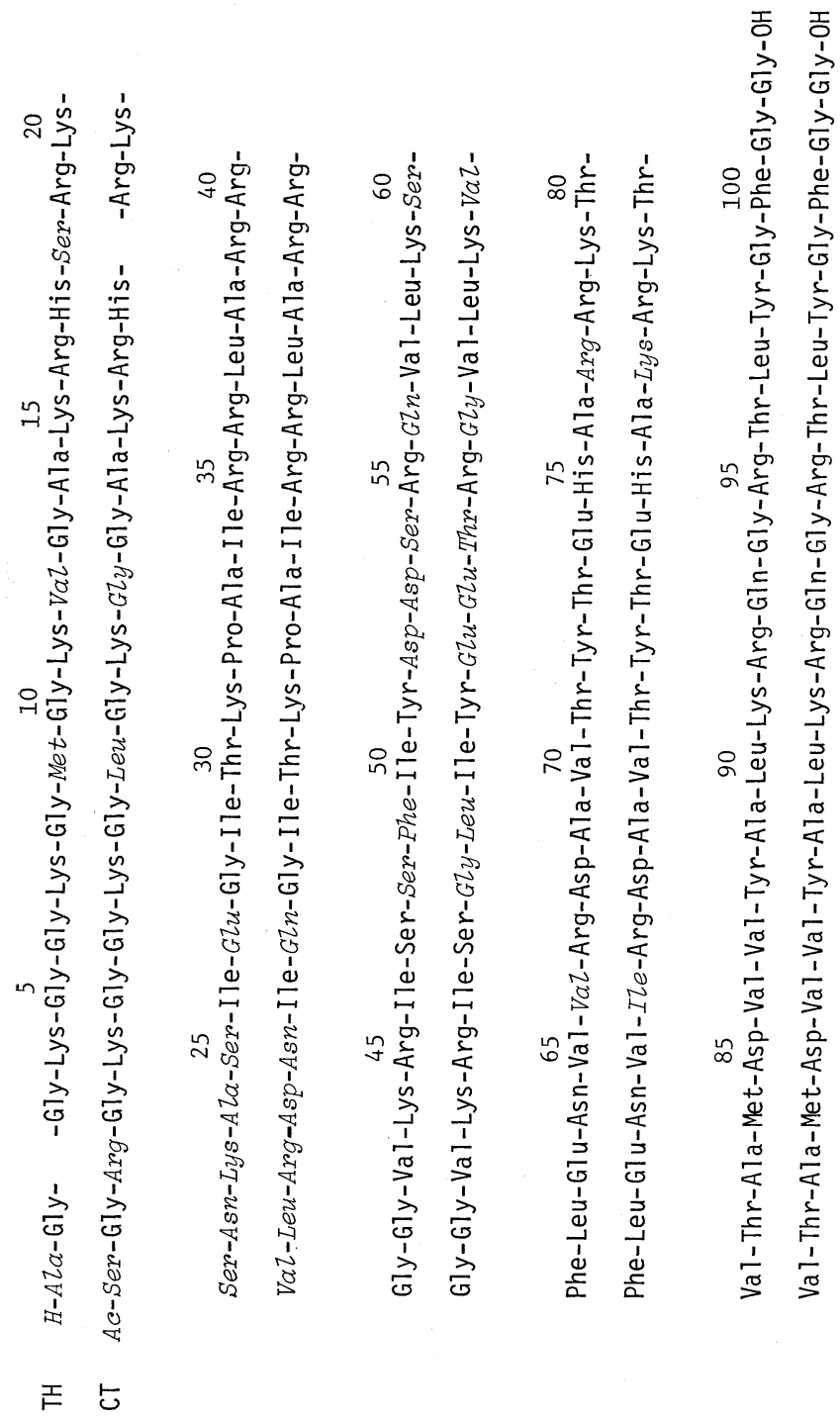

Fig. 1. Amino acid sequence of Tetrahymena (TH) histone H4, compared to that of calf thymus (CT) $\mathrm{H}_{4 .{ }^{1}{ }^{1}{ }^{2} \text { ) }}$ The two sequences have been aligned to obtain maximum homology. A minor variant (ca. 14\%) of Tetrahymena $\mathrm{H} 4$ has an additional arginine inserted between residues 88 and 89 , and thus contains a total of 103 residues.

rat $^{17), 18)}$ for $\mathrm{H} 4$, and between human, ${ }^{19)}$ calf, ${ }^{3)}$ and mouse ${ }^{20)}$ for $\mathrm{H} 2 \mathrm{~B}$. The five total sequences now available for $\mathrm{H} 4$ are all composed of 102 amino acid residues, while the calf, pea, and Tetrahymena H2B sequences contain 125, 132 or 133, and 119 residues, respectively. These H2B sequences can be divided into a variable (not homologous) amino-terminal region (34, 39 or 40 , and 28 residues, respectively) 


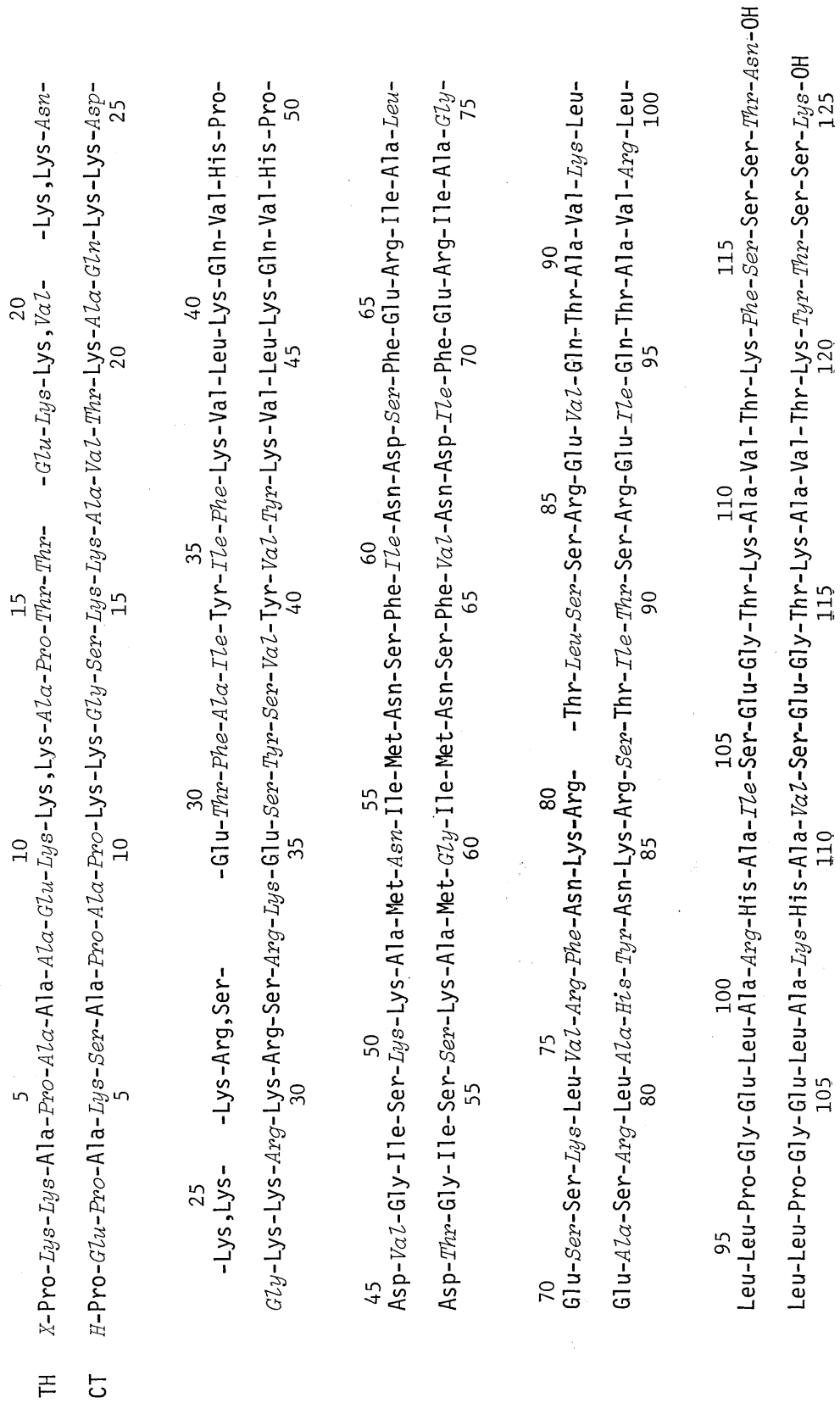

Fig. 2. Amino acid sequence of Tetrahymena (TH) histone H2B, compared to that of calf thymus (CT) H2B. ${ }^{3}$ The two sequences have been aligned to obtain maximum homology. "The amino-terminal sequence of Tetrahymena $\mathrm{H} 2 \mathrm{~B}$ is tentative.

and a conserved middle to carboxy-terminal region (91, 93, and 91 residues, respectively). 


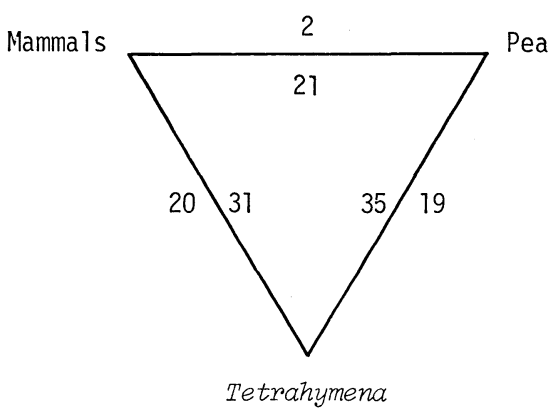

Fig. 3. Percent difference in the $\mathrm{H} 4$ and H2B sequences between mammals (see text), pea, and Tetrahymena. The data for the H4 sequences are indicated outside the triangle, and show differences in the total sequence. The data for the H2B sequences, indicated inside, represent differences in the conserved middle to carboxy-terminal region (see text).

For the $\mathrm{H} 4$ sequences, the differences of only two residues (2\% in the total sequence) between calf and pea are already known. ${ }^{7)}$ Now we have found differences of 20 residues (20\%) between Tetrahymena and calf and differences of 19 residues (19\%) between Tetrahymena and pea. For the H2B sequences, we have already shown differences of 19 residues $(21 \%)$ in the conserved region between calf and pea, in addition to differences of maximal 34 to 40 residues in the variable region.9) Now, the corresponding differences of $28+(28 / 34)$ residues (31\% in the conserved region) between Tetrahymena and calf, and differences of $32+(28 / 40)$ residues $(35 \%)$ between Tetrahymena and pea have been found. Thus in both the cases of the H4 and H2B sequences, the homology between the mammal and the plant is clearly higher than that between the protozoan and the mammal or plant.

These data strongly imply that the divergence of the lines leading to protozoa and to higher eukaryotes is ancient and substantially antedates the divergence of the lines leading to higher animals and plants. A similar conclusion is reached from cytochrome $c$ sequences, including those of Tetrahymena pyriformis and three fragellates, suggesting that the divergence of protista is more ancient than the animal/plant divergence, and that Tetrahymena appears to have diverged even earlier than Euglena and Crithidia, 1.4 billion years ago. ${ }^{12)}$ For more detailed analysis of very distant evolutionary events, more abundant histone sequences, particularly of lower eukaryotes, need to be determined.

Summary. The total and partial amino acid sequences of Tetrahymena histones $\mathrm{H} 4$ and $\mathrm{H} 2 \mathrm{~B}$, respectively, have been determined. Comparisons of these sequences with those of mammals and pea sug- 
gest that the divergence of protozoa and higher eukaryotes is more ancient than the divergence of animals and plants.

Acknowledgement. This study was supported in part by a Grantin-Aid for Scientific Research from the Ministry of Education, Science and Culture of Japan.

\section{References}

1) DeLange, R. J., Fambrough, D. M., Smith, E. L., and Bonner, J.: J. Biol. Chem., 244, 319-334 (1969).

2) Ogawa, Y., Quagliarotti, G., Jordan, J., Taylor, C. W., Starbuck, W. C., and Busch, H.: J. Biol. Chem., 244, 4387-4392 (1969).

3) Iwai, K., Ishikawa, K., and Hayashi, H.: Nature, 226, 1056-1058 (1970).

4) Hayashi, H., and Iwai, K.: J. Biochem., 70, 543-547 (1971).

5) Yeoman, L. C., Olson, M. O. J., Sugano, N., Jordan, J. J., Taylor, C. W., Starbuck, W. C., and Busch, H.: J. Biol. Chem., 247, 6018-6023 (1972).

6) DeLange, R. J., Hooper, J. A., and Smith, E. L.: J. Biol. Chem., 248, 32613274 (1973).

7) DeLange, R. J., Fambrough, D. M., Smith, E. L., and Bonner, J.: J. Biol. Chem., 244, 5669-5679 (1969).

8) Patthy, L., and Smith, E. L.: J. Biol. Chem., 248, 6834-6840 (1973).

9) Hayashi, H., Iwai, K., Johnson, J. D., and Bonner, J.: J. Biochem., 82, 503-510 (1977).

10) Iwai, K., Shiomi, H., Ando, T., and Mita, T.: J. Biochem., 58, 312-314 (1965).

11) Iwai, K., Hamana, K., and Yabuki, H.: J. Biochem., 68, 597-601 (1970).

12) Dayhoff, M. O.: Atlas of Protein Sequence and Structure. vol. 5, suppl. 3. National Biomedical Research Foundation, Washington, D.C. (1978).

13) Hamana, K., and Iwai, K.: J. Biochem., 69, 1097-1111 (1971).

14) — : J. Biochem., 86, 789-794 (1979).

15) Glover, C. V. C., and Gorovsky, M. A.: Proc. Natl. Acad. Sci. USA, 76, 585-589 (1979).

16) Sautière, P., Lambelin-Breynaert, M.-D., Moschetto, Y., and Biserte, G.: Biochimie; 53, 711-715 (1971).

17) Wilson, R. K., Starbuck, W. C., Taylor, C. W., Jordan, J., and Busch, H.: Cancer Res., 30, 2942-2951 (1970).

18) Sautière, P., Tyrou, D., Moschetto, Y., and Biserte, G.: Biochimie, 53, 479483 (1971).

19) Ohe, Y., Hayashi, H., and Iwai, K.: J. Biochem., 85, 615-624 (1979).

20) Franklin, S. G., and Zweidler, A.: Nature, 266, 273-275 (1977). 